\section{Antibiosis to Beet Armyworm (Spodoptera exigua) in Lycopersicon Accessions}

\author{
Sanford D. Eigenbrode ${ }^{1}$ and John T. Trumble \\ Department of Entomology, University of California, Riverside, CA 92521
}

Additional index words. host-plant resistance, tomato, trichomes, sesquiterpene hydrocarbons, methylketones, Lycopersicon hirsutum f. glabratum, Lycopersicon hirsutum f. typicum

Abstract. Four accessions of Lycopersicon hirsutum f. glabratum Mull. and eight accessions of $L$. hirsutum f. typicum Humb. \& Bonpl. were evaluated for their resistance to the beet armyworm [Spodoptera exigua (Hübner)]. Survival of S. exigua neonate larvae for up to 96 hours on foliage of all these accessions differed significantly from their survival on a susceptible tomato cultivar. Spodoptera exigua survival did not differ significantly between the two forms of $L$. hirsutum. Antibiosis to $S$. exigua in L. hirsutum f. glabratum appears similar to the levels found to other Lepidoptera. Accessions of L. hirsutum $f$. typicum included the very susceptible PI 199381 and the two most resistant accessions, LA 2329 and LA 1777. Insect resistance had not been reported previously in four of the $L$. hirsutum f. typicum accessions. Spodoptera exigua survival was significantly negatively correlated with the density of type IV glandular trichomes on the leaf surfaces, calculated across all 12 accessions. This relationship did not occur within L. hirsutum f. glabratumor L. hirsutum f. typicum accessions, nor was it significant if PI 199381 was excluded from the analysis. Leaf-surface exudates of $L$. hirsutum f. glabratum accessions were dominated by the methylketones 2-undecanone and 2-tridecanone. Leaf-surface exudates of $L$. hirsutum f. typicum were dominated by three sesquiterpenes-zingiberene, $\delta$ - elemene, and $\gamma$ elemene. Resistance was not correlated with the amounts of these specific compounds within or across botanical form. Spodoptera exigua survival in L. hirsutum f. typicum (excluding PI 199381) correlated negatively with the total estimated amount of leaf-surface volatiles extracted. PI 199381 may be useful as a susceptible parent for intraspecific crosses to examine $S$. exigua resistance in $L$. hirsutum.

The beet armyworm rapidly is becoming the most important lepidopteran tomato pest in California and Mexico (Brewer et al., 1990). Tomatoes withresistance to Spodoptera exigua will be important for the alternative management strategies needed to control this insect in the future. Identifying suitable sources of resistance to this insect and understanding the mechanisms of this resistance are prerequisites for developing resistant tomato varieties.

Antibiosis to Lepidoptera, including S. exigua, has been reported in accessions of both botanical forms of Lycopersicon hirsutum (f. typicum and f. glabratum) (Farrar and Kennedy, 1992). Most research has focused on the mechanisms and inheritance of antibiosis to several lepidopteran pests in glabratum accession PI 134417 (Farrar and Kennedy, 1992).

Received for publication 22 Dec. 1992. Accepted for publication 24 Apr. 1993. We thank J.G. Millar for his consultation regarding the chemical analyses and for performing the mass spectrometry; W.G. Carson, K.K. White, and S. Williams for their technical assistance; and M.M. Diawara, J.R. McFerson, and J.G. Millar for their helpful discussion and review of the manuscript. The research was supported in part by the California Tomato Board. The cost of publishing this paper was defrayed in part by the payment of page charges. Under postal regulations, this paper therefore must be hereby marked advertisement solely to indicate this fact.

${ }^{1}$ To whom reprint requests should be addressed. Present address: Dept. of Entomology, 410 Forbes Bldg., Univ. of Arizona, Tucson, AZ 85721.
The first objective of the present study was to evaluate the level of antibiosis to S. exigua identify other sources of antibiosis to $S$. exigua within $L$. hirsutum to broaden the potential base of resistance in breeding programs. The third objective was to examine the role of glandular trichomes and their secretions in producing antibiosis in the tested accessions.

Many studies implicate trichome secretions as important resistance factors in $L$. hirsutum to insects (Farrar and Kennedy, 1992). All glabratum accessions examined secrete methylketones in their type VI trichomes. (Trichome types in this paper are after Luckwill, 1943.) These compounds are toxic to several arthropod pests, including S. exigua, and are responsible for antibiosis in PI 134417 to several insects (Kennedy and Dimock, 1983; Kennedy and Farrar, 1987; Lin and Trumble, 1986; Williams et al., 1980). In typicum, resistance to arthropods also is related to the secretions or densities of glandular trichomes. Sesquiterpene hydrocarbons present in type VI trichomes of some typicum accessions are highly toxic to tomato pests, including $S$. exigua (Carter et al., 1989a, 1989b; Lin et al., 1987). Resistance to S. exigua and spider mites also has been associated with densities of type IV glandular trichomes in L. esculentum $\times$ typicum populations, but causality has not been established (Good and Snyder, 1988).

Four glabratum and eight typicum accessions were included in the study (Table 1). in PI 134417. The second objective was to
Accessions were obtained either from the C.M. Rick Tomato Genetic Resources Center, Univ. of California (UC), Davis, or the U.S. Dept. of Agriculture, Agricultural Research Service, Plant Genetic Resources Unit, Geneva, N.Y. The glabratum accessions included three Ecuadorian and one Peruvian accession (PI 126445). The typicum accessions were from eight locations ranging from lat. $7^{\circ}$ to $13^{\circ} \mathrm{S}$ and 1200 to $2920 \mathrm{~m}$ above sea level. This includes much of the geographic range of the taxon (Rick et al., 1978; Wamock, 1991). More typicum accessions were tested because typicum is genetically more diverse than glubratum (Rick et al., 1978) and an effort was made to include some of this genetic diversity in the sample. Seven of the accessions had been reported previously as resistant to at least one other arthropod pest (Farrar and Kennedy, 1992). Arthropod resistance had not been reported previously in typicum accessions LA 1363, LA 1737, LA 1927, and LA 2329. PI 199381 was included as a typicum accession, although some consider it to be a misclassified glabratum accession (Weston et al., 1989). Two PI 199381 lots, which had markedly different leaf sizes when grown under similar greenhouse conditions, were tested separately. One of the lots could not be identified; thus, it will be identified as PI 199381a in this paper; 'Beltsville 1985 increase' will be designated as PI 199381b. A susceptible L. esculentum cultivar, 'VFN 7718' (Petoseed, Woodland, Calif.), was included in the experiments as a control.

Seeds were sown 8 Jan. 1992, and the plants were grown in pots with UC soil mix until the last week in March. Cuttings from three to four plants from each accession were established in pots and grown in the greenhouse under ambient light conditions and $\approx 20 /$ $30 \mathrm{C}$ night/day until tests were conducted in July.

Resistance was assessed by measuring survival of first-instar $S$. exigua on leaf tissue from these 14 test entries. Spodoptera exigua eggs were obtained from a laboratory colony maintained by Mycogen (San Diego). Four replications of newly hatched larvae were reared on leaflets from about the fourth node from the terminal of each test plant. Each replication consisted of 10 larvae reared together in a $200-\mathrm{ml}$ waxed-paper cup partially filled with water-agar gel to maintain moisture (Diawara et al., 1992). Leaflets were replaced every $24 \mathrm{~h}$ and the number of larvae surviving after $96 \mathrm{~h}$ was recorded. The reason for the short duration of this bioassay was to obtain discrimination among the accessions, since survival over longer periods approaches zero in many of them. In addition, the short duration is justified because larvae begin to feed on fruit after the third-instar stage, and resistance that is effective for the first $96 \mathrm{~h}$ is most desirable. The test was conducted on 6 July and again on 10 July. Data from these two tests were combined for a total of eight replications (80 larvae) for each test plant.

On 8 July, leaf-surface exudates were extracted from about the fifth leaf from the terminal of each test plant. About $30 \mathrm{~cm}^{2}$ of 
Table 1. Survival for up to $96 \mathrm{~h}$ of neonate Spodoptera exigua larvae, trichome densities, and concentration of leaf-surface compounds on the foliage of wild tomato (Lycopersicon) accessions and the susceptible cultivar VFN 7718

\begin{tabular}{|c|c|c|c|c|c|c|c|c|c|}
\hline \multirow{3}{*}{$\begin{array}{l}\text { Species and } \\
\text { accession }^{y}\end{array}$} & \multirow{3}{*}{$\begin{array}{c}\text { S. exigua } \\
\text { survival }^{z} \\
(\%)\end{array}$} & \multirow{2}{*}{\multicolumn{2}{|c|}{$\begin{array}{c}\text { Trichome } \\
\text { density } \\
\left(\mathrm{mm}^{2}\right)\end{array}$}} & \multicolumn{6}{|c|}{ Leaf-surface compounds $\left(\mu \mathrm{g} \cdot \mathrm{cm}^{-2}\right)$} \\
\hline & & & & \multirow[b]{2}{*}{ 2-Undecanone } & \multirow[b]{2}{*}{ 2-Tridecanone } & \multirow[b]{2}{*}{$\delta$-Elemene } & \multirow[b]{2}{*}{$\gamma$-Elemene } & \multirow[b]{2}{*}{ Zingiberene } & \multirow{2}{*}{$\begin{array}{c}\text { Total } \\
\text { volatiles }^{x}\end{array}$} \\
\hline & & IV & VI & & & & & & \\
\hline \multicolumn{10}{|l|}{ L. esculentum } \\
\hline VFN 7718 & $85.2 \mathrm{a}$ & $0.1 \mathrm{e}$ & $15.5 b$ & 0 & 0 & 0 & 0 & 0 & 0.47 \\
\hline \multicolumn{10}{|c|}{ L. hirsutum f. glabratum } \\
\hline PI 126304 & $2.2 \mathrm{f}-\mathrm{h}$ & $10.9 \mathrm{~cd}$ & $9.0 \mathrm{~b}-\mathrm{d}$ & 5.54 & 22.97 & 0 & 0.87 & 0 & 39.46 \\
\hline PI 126449 & $1.7 \mathrm{gh}$ & $10.4 \mathrm{~cd}$ & $9.2 \mathrm{~b}-\mathrm{d}$ & 3.62 & 13.20 & 0 & 0 & 0 & 24.20 \\
\hline PI 134417 & $6.7 \mathrm{de}$ & $13.4 \mathrm{~b}-\mathrm{d}$ & $9.8 b-d$ & 5.37 & 16.94 & 0 & 0.90 & 0 & 32.10 \\
\hline PI 134418 & $1.1 \mathrm{~h}$ & $11.9 \mathrm{~cd}$ & $8.8 \mathrm{~b}-\mathrm{d}$ & 4.98 & 14.97 & 0 & 0 & 0 & 28.0 \\
\hline \multicolumn{10}{|c|}{ L. hirsutum f. typicum } \\
\hline PI 199381a & $37.9 \mathrm{c}$ & $0.0 \mathrm{e}$ & $4.5 \mathrm{~d}$ & --- & --- & --- & --- & --- & --- \\
\hline PI 199381b & $55.8 \mathrm{~b}$ & $0.5 \mathrm{e}$ & $14.7 \mathrm{bc}$ & 0 & 0.07 & 0.13 & 0.07 & 0 & 0.26 \\
\hline PI 126445 & $9.7 \mathrm{~d}$ & $21.9 \mathrm{ab}$ & $9.0 \mathrm{~b}-\mathrm{d}$ & 0 & 0 & 0.81 & 3.33 & 13.89 & 41.50 \\
\hline PI 127827 & $2.7 \mathrm{e}-\mathrm{h}$ & $24.8 \mathrm{a}$ & $8.3 \mathrm{~b}-\mathrm{d}$ & 0 & 0 & 0 & 2.60 & 2.27 & 173.90 \\
\hline LA 2329 & $0.6 \mathrm{~h}$ & $16.8 \mathrm{ab}$ & $27.5 \mathrm{a}$ & 0 & 0 & 0.06 & 8.29 & 14.23 & 202.50 \\
\hline LA 1363 & $6.1 \mathrm{~d}-\mathrm{f}$ & $15.3 \mathrm{~b}-\mathrm{d}$ & $6.2 \mathrm{~cd}$ & 0 & 0 & 0.40 & 0 & 0 & 0.51 \\
\hline LA 1737 & $5.8 \mathrm{~d}-\mathrm{f}$ & $21.2 \mathrm{ab}$ & $9.6 \mathrm{~b}-\mathrm{d}$ & 0 & 0 & 0 & 0.98 & 0 & 4.22 \\
\hline LA 1777 & $0.9 \mathrm{~h}$ & $22.0 \mathrm{ab}$ & $16.2 \mathrm{~b}$ & 0 & 0 & 0.69 & 9.98 & 0 & 58.79 \\
\hline LA 1927 & $4.3 \mathrm{~d}-\mathrm{g}$ & $6.8 \mathrm{de}$ & $17.8 \mathrm{ab}$ & 0 & 0 & 0.28 & 4.51 & 0 & 6.88 \\
\hline
\end{tabular}

${ }^{2}$ Mean separation by protected LSD at $P \leq 0.05$.

${ }^{y}$ PI accessions were obtained from the U.S. Dept. of Agricutlure, Agricultural Research Service, Plant Genetic Resources Unit, Geneva, N. Y. LA accessions were obtained from the C.M. Rick Tomato Genetic Resources Center, Univ. of California, Davis.

${ }^{x}$ Approximate amount on leaf surface based on area counts compared with tetradecane standard.

leaf material from each plant was extracted for $1.5 \mathrm{~h}$ with agitation in $10 \mathrm{ml}$ high-performance liquid chromatography (HPLC)-grade hexane containing an internal standard of dodecane $\left(30 \mu \mathrm{g} \cdot \mathrm{ml}^{-1}\right)$. The extract was decanted and restored to a volume of $10.0 \mathrm{ml}$ with HPLCgrade hexane. These extracts were stored for 2 weeks at $-20 \mathrm{C}$, then analyzed with gas chromatography-mass spectroscopy (GC-MS) for the presence of major sesquiterpenes and two methylketones. All extracts were analyzed with a gas chromatograph (model 5890, series II; Hewlett-Packard, Avondale, Pa.) fitted with an autosampler (model 7673; Hewlett-Packard) and a flame ionization detector (FID). Data were recorded with an integrator (model 3396; Hewlett-Packard). Injections were made in the splitless mode. A $60-\mathrm{m} \times 0.25-\mathrm{mm}$-i.d. DB-5 column (J\&W Scientific, Folsom, Calif.) was used, with a temperature program of $100 \mathrm{C}$ to start, $15 \mathrm{C} / \mathrm{min}$ to $200 \mathrm{C}, \mathrm{SC} / \mathrm{min}$ to $250 \mathrm{C}$, then $20 \mathrm{C} / \mathrm{min}$ to $300 \mathrm{C} / 10 \mathrm{~min}$. Helium was used as the-carrier gas. Representative extracts were analyzed further by GC-MS using a gas chromatograph interfaced to a mass selective detector (model 5870; HewlettPackard). Analyses were carried out with a 20$\mathrm{m} \times 0.2 \mathrm{~mm}$-i.d. DB-5 column, using the temperature program described above. Zingiberene, 2-undecanone, and 2-tridecanone were identified positively by matching retention times and mass spectra with those of authentic standards. An authentic zingiberene standard was extracted from ginger root; 2-undecanone and 2-tridecanone were obtained from $\mathrm{K}$ and K Laboratories (Plainview, N.Y.). Elemenes ( $\delta$ and $\gamma$ were identified by matching their mass spectra and retention times with those of compounds in a mixture of elemene isomers obtained by dehydrating elemol (Millar et al., 1985). All of these compounds are known major constituents of trichome exudates of typicum or glabratum accessions (Eigenbrode et al., unpublished data; Weston et al., 1989).
In addition to the principal sesquiterpenes and methylketones, many other volatile compounds in the leaf-surface extracts were separated by the above GC method. Most of these were eluted during the first $15 \mathrm{~min}$ after injection. After $15 \mathrm{~min}$, GC traces were dominated by regularly spaced peaks of the dominant alkanes in the leaf-surface waxes. The volatile compounds occurring in the first 15 min were not identified, but the total FID signal area of these compounds also was recorded for each extract and used to compute an approximate concentration of these volatiles on the leaf surface. This total relative signal is only approximate because scaling factors for the unknowns cannot be determined. Since these compounds bracket the internal standard's retention time, the approximation should be reasonable.

During the week of 13 July, the densities of type IV and type VI glandular trichomes were determined on distal leaflets from leaves from the third node from the terminal of each test plant. Four leaves from each plant were examined at $\times 60$ with a stereoscopic dissecting microscope, and all trichomes were counted on a $2.2-\mathrm{mm}^{2}$ area of the upper and lower surface of each leaf. The mean number of each trichome type per square millimeter of each plant was calculated from these data.

Spodoptera exigua survival and trichome densities were tested with analysis of variance. Each plant within an accession was considered one replication and the mean response of the within-plant replicates was treated as one observation. Since the mean square error for the two sequential bioassays did not differ, the data from the two tests were combined for analysis. Survival data were transformed to the $\arcsin \sqrt{x}$ to stabilize variances before analysis. Trichome count data were not transformed. Means were separated with a protected least significant difference test. Pearson's correlation coefficients were deter- mined between nontransformed S. exigua survival, trichome densities, concentrations of the identified exudate components, and the total approximate concentration of volatiles eluting in $15 \mathrm{~min}$. All analyses were performed using SAS's MEANS, CORR, and GLM procedures (SAS Institute, 1990).

Spodoptera exigua survival was significantly less on all glabratum and typicum accessions than on the susceptible cultivar VFN 7718 (Table 1). Survival on both lots of PI 199381 was significantly higher than on the other accessions and these lots may be considered susceptible to $S$. exigua. The lack of resistance in PI 199381 contrasts previous reports of resistance in this accession to other arthropods (e.g., Schuster, 1977; Weston et al., 1989). PI 199381 lots are known to differ in several traits (J.R. McFerson, personal communication), a fact that may account for this discrepancy. Alternatively, S. exigua may be tolerant to resistance in PI 199381.

Spodoptera exigua survival was low on the remaining 10 test accessions, ranging from $9.7 \%$ to $0.9 \%$. This result indicated that these accessions have antibiosis to S. exigua. Excluding PI 199381, S. exigua survival did not differ significantly between glabratum and typicum accessions (glabratum 3.0\% $\pm 0.9 \%$ vs .typicum $5.1 \% \pm 0.8 \%, P=0.1096$, Student's t test). PI 134417 and PI 126445, which have been studied extensively as sources of resistance to Lepidoptera, spider mites, and the Colorado potato beetle (Carter et al., 1989a, 1989b; Kennedy and Dimock, 1983; Weston et al., 1989) were not as resistant to S. exigua in our study as the other typicum and glabratum accessions. The lowest S. exigua survival occurred on typicum accessions LA 1777 and LA 2329. This result is consistent with a previous report of high levels of lepidopteran resistance in LA 1777 (Juvik et al., 1982). Resistance in LA 2329 has not been reported previously.

As expected from previous reports (Weston 
et al., 1989), glabratum leaf-surface exudates were dominated by methylketones and those of typicum were dominated by sesquiterpenes (Table 1). Methylketones were absent from the typicum accessions and only small amounts of the sesquitetpene $\gamma$-elemene were found on two glabratum accessions. Methylketones comprised an average of $75 \%$ of the GCdetectable volatiles on the four glabratum accessions tested, and their relative concentrations were similar in all four. These concentrations closely agree with those previously reported for these accessions under long-day conditions (Kennedy and Dimock, 1983; Weston et al., 1989). In contrast to previous reports, however, zingiberene did not dominate typicum extracts. It was absent on all typicum accessions from the LA series except LA 2329. We found $50 \%$ and $90 \%$ less zingiberene on PI 126445 and PI 127827 , respectively, than Weston et al. (1989) under similar conditions. We also found nearly 100 and 20 times as much $\gamma$-elemene on these two accessions as Weston et al. (1989). Surface chemistry was measured only on PI $199381 \mathrm{~b}$ and not on PI 199381a. The former was the only typicum with detectable quantities of methylketones; sesquiterpene concentrations were very low.

The chemical composition of leaf-surface exudate was much more variable among typicum than glabratum accessions in the amounts of different compounds in the leafsurface exudate (Table 1) and number of specific compounds. The total number of volatile compounds registering as detectable peaks (threshold of 10,000 area units) in the first 10 min of our GC runs ranged from one to thirteen in typicum but was two or three in glabratum accessions. The three principal sesquiterpenes comprised $17 \%$ to $100 \%$ of the GC-detectable volatiles on typicum.

Lycopersicon hirsutum f. typicum accessions had higher average densities of both types of trichomes than glabratum (Table 1). As with surface chemistry, densities of type IV and type VI trichomes were much more variable among typicum than glabratum accessions.

Spodoptera exigua survival correlated negatively with type IV trichome density among the 12 test accessions $(-0.659, P=$ $0.0001)$. This correlation agrees with other reported correlations between type IV trichome densities and arthropod resistance among $L$. hirsutum accessions (Weston et al., 1989) and L. esculentum $\times$ L. hirsutum interspecific populations (Eigenbrode et al., unpublished data; Good and Snyder, 1988). The correlation suggests that densities of type IV trichomes or linked traits directly decrease $S$. exigua survival. However, the strength of the relationship in the present study depended on including PI 199381; excluding this accession, there was no significant relationship between type
IV or type VI trichome densities and S. exigua survival across or within botanical forms. Within typicum, the relationship for type VI trichomes was marginal $(-0.394, P=0.060)$. Correlation analysis also revealed no significant relationships between $S$. exigua survival and the presence or concentration of specific compounds across or within both botanical forms. This analysis included approximate concentrations of 15 unidentified major peaks in the chromatograms and the identified methylketones and sesquiterpene hydrocarbons. Within typicum (excluding PI 199381), survival correlated negatively with total chromatogram area of volatiles eluting in the first $15 \min (-0.447, P=0.032)$.

PI 199381 was unique among the accessions studied because of its extreme susceptibility relative to all other $L$. hirsutum accessions and because of the low counts of type IV trichomes and low concentrations of volatiles on its leaf surfaces. These observations suggest that these two general or linked characteristics are critical for resistance in L. hirsutum to $S$. exigua. Whatever the mechanisms are, their elucidation may be facilitated by using PI 199381 as a susceptible parent to obtain typicum populations segregating for resistance.

The intensity of antibiosis to $S$. exigua was similar in the typicum and glabratum accessions tested. The greater variation in typicum in the intensity of antibiosis and in trichome densities and the composition of their secretions suggests that additional screening for resistance may be more productive in typicum than in glabratum. The greater complexity of the leaf-surface exudates from typicum may indicate that resistance among these accessions is conditioned by multiple traits at the leaf surface. Incorporating this resistance into L. esculentum may be problematic if it depends on many genes. However, specific resistance mechanisms must be elucidated to assess this possibility. Additional study of resistance in LA 1777 and LA 2329 is merited to evaluate their potential as sources of resistance to S. exigua.

\section{Literature Cited}

Brewer, M.J., J.T. Trumble, B.Alvarado-Rodriquez, and W.E. Chaney. 1990. Beet armyworm (Lepidoptera: Noctuidae) adult and larval susceptibility to three insecticides in managed habitats and relationship to laboratory selection for resistance. J. Econ. Entomol. 83:2136-2146.

Carter, C.D, T.J. Gianfagna, and J.N. Sacalis. 1989a. Sesquiterpenes in glandular trichomes of a wild tomato species and toxicity to the Colorado potato beetle. J. Agr. Food Chem. 37:14251428.

Carter, C.D., J.N. Sacalis and T.J. Gianfagna. 1989b. Zingiberene and resistance to the Colorado potato beetle in Lycopersicon hirsutum f. hirsutum. J. Agr. Food Chem. 37:206-210.

Diawara, M.M., J.T. Trumble, CF. Quiros, and J.G.
Millar. 1992. Resistance to Spodoptera exigua in Apium prostratum. Entomol. Expt. Applicata 64:125-133.

Dimock, M.B. and G.G. Kennedy. 1983. The role of glandular trichomes in the resistance of Lycopersicon hirsutum f. glabratum to Heliothis zea. Entomol. Expt. Applicata 33:263-268.

Farrar, R.R. and G.G. Kennedy. 1992. Sources of insect and mite resistance in tomato in Lycopersicon spp., p. 121-142. In: G. Kalloo (ed.). Monographs on theoretical and applied genetics. 14. Genetic improvement of tomato. Springer-Verlag, Berlin.

Good, D.E., Jr., and J.C. Snyder. 1988. Seasonal variation of leaves and mite resistance of Lycopersicon interspecific hybrids. HortScience 23:891-894.

Juvik, J.A., M.J. Behringer, T. Ben-David, and J. Rudlich. 1982. Resistance among accessions of the genera Lycopersicon and Solanum to four of the main insect pests of tomato in Israel. Phytoparasitica 10:145-156.

Kennedy, G.G. and M.B. Dimock. 1983. 2Tridecanone: A natural toxicant in a wild tomato responsible for insect resistance. Proc. 5th Intl. Congr. Pest. Chem. p. 123-128.

Kennedy, G.G. and R.R. Farrar, Jr. 1987. Response of insecticide-resistant and susceptible Colorado potato beetles, Leptinotarsa decemlineata to 2-tridecanone and resistant tomato foliage: The absence of cross resistance. Entomol. Expt. Applicata 45: 187-192.

Lin, S.Y.H. and J.T. Trumble. 1986. Resistance in wild tomatoes to larvae of a specialist herbivore, Keiferia lycopersicella. Entomol. Expt. Applicata 41:53-60.

Lin, S.Y.H., J.T. Trumble, and J. Kumamoto. 1987. Activity of volatile compounds in glandular trichomes of Lycopersicon species against two insect herbivores. J. Chem. Ecol. 13:837-850.

Luckwill, L.C. 1943. The genus Lycopersicon: An historical, biological, and taxonomic survey of the wild and cultivated tomatoes. Aberdeen Univ. Press, Scotland. no. 120.

Millar, J.G., C.-H. Zhao, G.N. Lanier, D.P O'Callaghan, M. Griggs, J.R. West, and R.M. Silverstein. 1986. Components of moribund American elm trees as attractants to elm bark beetles, Hylurgopinus rufipes and Scolytus multistriatus. J. Chem. Ecol. 12:583-608.

Rick, C.M., J.F. Fobes, and S.D. Tanksley. 1978. Evolution of mating systems in Lycopersicon hirsutum as deduced from genetic variation in electrophoretic and morphological characters. Plant Systematic Evolution 132:279-298.

SAS Institute. 1990. SAS/STAT user's guide. SAS Institute, Cary, N.C.

Schuster, D.J. 1977. Effect of tomato cultivars on insect damage and chemical control. Florida Entomol. 60:227-232.

Warnock, S.J. 1991. Natural habitats of Lycopersicon species. HortScience 26:466-471.

Weston, P.A., D.A. Johnson, H.T. Burton, and J.C. Snyder. 1989. Trichome secretion composition, trichome densities, and spider mite resistance of ten accessions of Lycopersicon hirsutum. J. Amer. Soc. Hort. Sci. 114:492-498.

Williams, W.G., G.G. Kennedy, R.T. Yamamoto, J.D. Thacker, and J. Bordner. 1980. Twotridecanone: A naturally occurring insecticide from the wild tomato Lycopersicon hirsutum $\mathrm{f}$. glabratum. Science 207:888-889. 